\title{
Racismo estrutural e seus efeitos necropolíticos no ensino superior: a aplicação da justiça restaurativa como instrumento de efetividade da educação igualitária e da justiça sociorracial
}

\author{
Structural racism and its necropolitical effects on higher education: the \\ application of restorative justice as an instrument of effectiveness of \\ egalitarian education and socioracial justice
}

\author{
Ana Paula da Silva Sotero \\ Mestranda em Direito \\ Universidade Federal da Bahia - UFBA. \\ Salvador, Bahia - Brasil. \\ anapaula_sotero@hotmail.com \\ Luciano de Oliveira Souza Tourinho \\ Pós-Doutor em Direitos Humanos \\ Universidad de Salamanca - USAL. \\ Salamanca - Espanha. \\ Doutor em Direito Público \\ Universidade Federal da Bahia - UFBA. \\ Salvador, Bahia - Brasil. \\ luciano.tourinho.jus@gmail.com
}

\begin{abstract}
Resumo: O presente estudo tem por objetivo analisar a aplicabilidade das práticas restaurativas como instrumentos de efetividade da justiça sociorracial e da educação igualitária no ensino superior. Verifica-se que a incidência do racismo decorrente do processo histórico de exclusão dos negros revela a ineficácia da garantia da igualdade racial no espaço acadêmico. Nesse sentido, os modelos restaurativos surgem como mecanismo de transformação da educação superior em espaço de diálogo e conscientização, a fim de erradicar a incidência necropolítica do racismo. Para delinear a proposta teóri ca, o estudo fará abordagem dialética sobre as marcas do racismo estrutural e da necropolítica brasileira na contemporaneidade, a partir do resgate à memória da escravidão e uso de dados estatísticos sobre as desigualdades raciais no ensino superior, desmistificando os entraves da efetividade das políticas afirmativas. Ademais, a pesquisa utilizará abordagem crítico-reflexiva sobre a possibilidade do uso da Justiça Restaurativa nas universidades como instrumento de pacificação social.
\end{abstract}

Palavras chave: ensino superior; justiça restaurativa; necropolítica; racismo.

Abstract: This study aims to analyze the applicability of restorative practices as instruments for the effectiveness of socio-racial justice and egalitarian education in higher education. It appears that the incidence of racism resulting from the historical process of exclusion of blacks reveals the ineffectiveness of guaranteeing racial equality in the academic space. In this sense, restorative models emerge as a mechanism for transforming higher education into a space for dialogue and awareness, in order to eradicate the necropolitical incidence of racism. To outline the theoretical proposal, the study will make a dialectical approach to the marks of structural racism and Brazilian necropolitics in contemporary times, from the rescue of slavery's memory and the use of statistical data on racial inequalities in higher education, demystifying the barriers to effectiveness affirmative policies. Furthermore, the research will use a critical-reflective approach on the possibility of using Restorative Justice in universities as an instrument of social pacification.

Key-words: university education; restorative justice. necropolitics. racism.

Cite como

(ABNT NBR 6023:2018)

SOTERO, Ana Paula da Silva; TOURINHO, Luciano de Oliveira Souza. Racismo estrutural e seus efeitos necropolíticos no ensino superior: a aplicação da justiça restaurativa como instrumento de efetividade da educação igualitária e da justiça sociorracial. Dialogia, São Paulo, n. 38, p. 1-21, e20454, maio/ago. 2021. Disponível em: https://doi.org/10.5585/38.2021.20454.

American Psychological Association (APA)

Sotero, A. P. da. S., \& Tourinho, L. de. O. S. (2021, maio/ago.). Racismo estrutural e seus efeitos necropolíticos no ensino superior: a aplicação da justiça restaurativa como instrumento de efetividade da educação igualitária e da justiça sociorracial. Dialogia, São Paulo, 38, p. 1-21, e20454.

https://doi.org/10.5585/38.2021.20454. 


\section{Introdução}

A formação histórico-social do Brasil revela que o país foi fundado sob as atrocidades da escravidão realizadas contra a população negra e indígena. Em nome da lógica capitalista colonial, o racismo surgiu como instrumento de diferenciação dos indivíduos pela cor da pele, trazendo uma nova denominação para o conceito de raça.

Nesse percurso histórico, o racismo foi o mecanismo de estruturação das desigualdades sociais na realidade brasileira, que ainda reverberam na contemporaneidade. Tal conjuntura nos conduz ao processo de vulnerabilidade necropolítica dos povos negros e na precarização das políticas assistenciais que permitam a concretização dos direitos humanos de forma igualitária.

Em um giro contemporâneo, o direito à educação também reflete os efeitos necropolíticos do racismo estrutural quando não oportuniza o acesso igualitário dos alunos nos ambientes de aprendizagem. Ademais, o espaço educacional ainda se apresenta como um meio de reprodução do racismo e de exclusão dos povos negros, por meio da discriminação e dos discursos de ódio contra a população negra e as políticas afirmativas raciais.

Diante desse contexto, o presente estudo tem por objetivo analisar a aplicabilidade das práticas restaurativas como instrumentos de efetividade da justiça sociorracial e da educação igualitária no ensino superior por meio da edificação de uma educação libertadora, pautada na concretização dos direitos humanos de forma igualitária.

Observa-se que, na verdade, o espaço universitário acaba corroborando para as práticas discriminatórias do racismo, uma vez que ainda presenciamos o silenciamento da participação do povo negro na realidade acadêmica, que se revela como verdadeiros entraves necropolíticos para a promoção da educação igualitária e da justiça sociorracial.

Nesse sentido, a Justiça Restaurativa surge no contexto educacional como proposta de oportunizar a reparação histórico-social de desigualdade nas universidades, promovendo a inclusão social efetiva da população negra, a partir do diálogo, do respeito e da possibilidade de construção de uma consciência cidadã para erradicação das marcas do racismo dentro das universidades e fora delas.

Para delinear a presente proposta teórica, o estudo fará uma abordagem dialética sobre as marcas do racismo estrutural e da necropolítica brasileira na contemporaneidade, a partir do resgate à memória da escravidão negra no país. Além disso, será feito uma análise documental dos dados oficiais das desigualdades raciais no Brasil e seu impacto no acesso ao direito à educação do ensino superior no país, desmistificando as formas recreativas do racismo simbólico no ambiente 
universitário e os entraves para a efetividade das políticas afirmativas de permanência estudantil da população negra.

Ademais, a incursão teórica utilizará uma abordagem crítico-reflexiva sobre a possibilidade do uso da Justiça Restaurativa no ambiente universitário como instrumento de superação da discriminação racial, oportunizando a criação de uma consciência coletiva para a promoção da igualdade.

\section{A necropolítica brasileira e os efeitos do racismo estrutural na formação do estado brasileiro}

A desigualdade sociorracial que se delineia na realidade brasileira tem se apresentado como instrumento balizador da estrutura do Estado de Direito, em que a concretização dos direitos humanos e o acesso às políticas públicas são conduzidos pelas marcas da necropolítica brasileira, que distingue os povos pela cor da pele e pela condição socioeconômica que vivem.

Nesse contexto, observamos que o racismo é utilizado como política de manutenção das desigualdades, em que a população negra e periférica é vulnerabilizada no acesso aos seus direitos e mantida à margem social, em um contexto necropolítico de exclusão dos povos no Estado de Direito. Nessa linha de intelecção, o acesso ao direito fundamental à educação está pautado nas raízes do racismo estrutural e revela a deficiência da concretização desse direito de forma igualitária.

A partir dessa conjuntura, faz-se necessário analisar o processo histórico de formação do Estado de Direito do Brasil, a fim de compreender os efeitos necropolíticos do racismo, que foi estruturado, de maneira simbólica, na construção social brasileira contemporânea. Diante disso, é preciso revisitar o passado e rememorar as marcas da escravidão e do extermínio do povo negro no território nacional para desmistificar as permanências das políticas de exclusão.

O processo histórico-social brasileiro nos revela que a escravidão e a dizimação dos povos indígenas e negros foram alicerces para a estrutura da sociedade colonial, que utilizou o critério da raça como instrumento de coisificação do corpo negro e indígena, para serem considerados como mercadorias na lógica capitalista da época. Por esse aspecto, salienta Schwarcz (2019), que as correntes da escravidão carregam consigo marcas indeléveis que se petrificam na realidade social por meio das desigualdades sociorraciais.

Nessa linha de intelecção, ao revisitar o passado de escravidão dos povos negros estamos trazendo à baila a ancestralidade dos povos que foram silenciados e humilhados. Por esse aspecto, a investigação se faz necessária não apenas para compreensão da formação do espaço social, mas também para dar voz à luta dos povos vulnerabilizados. 
Antes de analisar a escravidão negra, cumpre salientar que estes não foram os primeiros povos a serem escravizados no Brasil. O processo de colonização do país é marcado pela dizimação dos povos indígenas, que foram explorados pelos portugueses e obrigados a trabalhar na implantação da colônia.

A partir do século XVI, o Brasil iniciou a comercialização dos povos africanos como escravos para serem explorados nas colônias agrícolas do território nacional. Conforme salienta Holanda (1995), a escravidão da população negra era o substrato do comércio lucrativo da lógica capitalista colonial, que garantia a mão de obra sem onerosidade para as lavouras dos donos de terra por meio da compra de escravos. Os donos de terra, então, passavam a ser donos dos povos escravizados, explorando a força de trabalho da população negra sem contraprestação e mediante violência e humilhação.

Conforme salienta Mbembe (2018a), o sistema capitalista escravocrata teve longa duração diante da satisfação econômica da elite branca, que se beneficiava com a dizimação da população negra. Nesse sentido, Mbembe (2018b) assevera que a manutenção, por tanto tempo, desse sistema colonial tinha suas justificativas fundadas nas raízes do racismo, que determinava a exploração da vida negra para sustentar a soberania da elite branca. Sob esse viés de Estado Soberano era permitido realizar atrocidades com a vida humana, no intuito de enfraquecer a cultura, a história e a língua do povo a ser colonizado, destinado a sofrer a usurpação de suas almas e de seus corpos pela dominação da elite branca.

Esse critério de separação do povo colonizado para o povo colonizador, traz o conceito de racismo como elemento de desigualdade sociorracial. Nas lições de Fernandes (2008), ao se utilizar a cor da pele como instrumento biopolítico de determinação da escravidão, faz-se a transformação do conceito de raça. Nesse contexto, a raça passa a ser interpretada sob a perspectiva do racismo que se estrutura na sociedade e determina a soberania da elite branca, que, nas lições de Mbembe (2018a, p. 29) "dita quem pode viver e quem deve morrer. Por isso, matar ou deixar viver constituem os limites da soberania, seus atributos fundamentais."

O racismo, portanto, reforça a descaracterização da população negra como mera mercadoria, ao se estruturar como mecanismo de diferença social. $\mathrm{O}$ indivíduo deixa de ser identificado pela sua cultura, sua história, sua terra e seu povo e passa a ser despersonificado pela cor da pele, de maneira inferior ao povo branco, revelando a face mais cruel da escravidão. Segundo aduz Almeida (2018), o racismo passa a ser estrutural, pois está presente em todas as estruturas sociais a partir do passado da escravidão dos povos africanos. 
Conforme salienta Agamben (2007), a soberania do povo colonizador sob o povo colonizado pode ser considerada como um processo biopolítico de dupla escravização do corpo negro. Nessa perspectiva, a primeira escravidão é percebida com a imposição do racismo como instrumento de qualificação e diferenciação entre os povos negros para os povos brancos. Ao se realizar a imposição da supremacia branca, a escravidão revela a atrocidade mais cruel que o Estado possuiu de desconsiderar a vida do povo negro, a sua ancestralidade, sua cultura, seus reinos, por meio da humilhação violenta.

Já a segunda escravidão é percebida quando esses povos negros humilhados eram reduzidos a mercadoria para serem vendidos como meros objetos de lucro dos senhores de escravos nas colônias, separando-os de suas terras. Essa conjuntura revela o racismo, mais uma vez, como um mecanismo de soberania e estruturação da sociedade escravocrata, pelo que Foucault (1999) definiu como a biopolítica da lógica capitalista colonial, justificando a função assassina do Estado em nome do interesse econômico.

Após a abolição da escravidão, em 1888, o racismo permaneceu sendo instrumento de desigualdade sociorracial. Observa-se que, apesar de declarar extinta o sistema escravocrata no país, ainda não podemos dizer que superamos as raízes da escravidão. Conforme aduz Nascimento (2019), com a abolição, os negros deixaram de lutar pela sua liberdade, mas permaneceram lutando pelo direito de existir e de ter acesso aos direitos essenciais para a sobrevivência humana.

A permanência da desigualdade sociorracial foi intensificada após o período de escravidão, tendo em vista que a população negra deixou de ser vista como mercadoria, mas permanecia presa nas engrenagens do racismo estrutural que se petrificou, de forma simbólica na realidade social. Salienta Góes (2019, p. 12) que “a abolição da escravidão no Brasil acabou com o comércio de pessoas negras, mas não erradicou os cativeiros que os prendiam.”

A população negra se viu livre das correntes que aprisionavam seus corpos, mas permaneceu presa a uma sociedade racista, que exclui e marginaliza os povos negros e periféricos. Os efeitos indeléveis e deletérios do racismo estrutural enraizado desde o processo de escravidão são reflexos do que Mbembe (2018a) definiu como necropolítica, que se consubstancia na política de extermínio e exclusão dos grupos vulnerabilizados do convívio social. Em se tratando da realidade brasileira inferimos que a necropolítica perpassa pelas raízes do racismo estrutural, determinando quem vai ter acesso aos direitos fundamentais para vida digna pelo critério da cor da pele em um processo de desigualdade sociorracial.

Esse processo necropolítico brasileiro foi reforçado desde a abolição da escravatura, quando a liberdade dos escravos foi forjada sob o mito da benevolência da elite branca. Na verdade, 
o que percebemos é que a abolição da escravatura aconteceu porque o comércio de escravos já não era mais lucrativo e o Brasil era o único país que mantinha a escravidão, podendo culminar na fragilidade das relações comerciais com outros países.

Nesse sentido, assevera Nascimento (1978) que, ao colocar a população em liberdade houve o verdadeiro descarte dos povos negros que ficaram desassistidos de políticas de inclusão social e de uma justiça de transição para reparar as atrocidades sofridas durante o período de escravidão. Nessa linha de intelecção, Ribeiro (2006, p. 202) aduz que "a luta mais árdua do negro africano e de seus descendentes brasileiros foi, ainda é, a conquista de um lugar e de um papel de participante legítimo na sociedade nacional".

Diante desse cenário, Hilário (2016) pondera que os critérios econômicos que levaram ao fim da escravidão permitiram o descarte da população negra vulnerabilizada, uma vez que a mão de obra assalariada que era adotada no novo contexto de trabalho não foi destinada aos negros libertos, mas sim ocupados pelos imigrantes que vieram para o país, sob a justificativa de que os negros não eram capacitados. Nas lições de Moreira (2019), a não capacitação dos negros para ocuparem a mão de obra assalariada faz parte do processo necropolítico brasileiro, como estratégia de exclusão da população negra do desenvolvimento social.

Outro processo necropolítico do racismo estrutural foi a tentativa do Estado de estabelecer o mito da democracia racial, ao recontar a história social a partir da leitura da elite branca sobre a escravidão. Segundo Diwan (2007), a releitura da escravidão pelos brancos revela o uso do racismo recreativo como forma de dirimir o extermínio e o solapamento dos direitos humanos que aconteceram durante o período escravocrata.

Nesse contexto, o mito da democracia racial buscava personificar a figura do negro como uma alegoria domesticada, que aceitava a sua condição de escravo e vivia em harmonia no sistema colonial, como foi retratado pelo autor Gilberto Freyre, em sua obra Casa Grande e Senzala.

\footnotetext{
Na ternura, na mímica excessiva, no catolicismo em que se deliciam nossos sentidos, na música, no andar, na fala, no canto de ninar menino pequeno, em tudo que é expressão sincera de vida, trazemos quase todos a influência negra. Da escrava ou sinhama que nos embalou. Que nos deu de mamar. Que nos deu de comer, ela própria amolegando na mão o bolão de comida. Da negra velha que nos contou as primeiras histórias de bicho e de mal-assombrado. Da mulata que nos tirou o primeiro bicho de pé de uma coceira tão boa. Da que nos iniciou no amor físico e nos transmitiu, ao ranger da cama de vento, a sensação completa de homem. Do muleque que foi o nosso primeiro companheiro de brinquedo. (FREYRE, 2002, p. 301).
}

Tal conjuntura reverbera no processo de invisibilização da memória da escravidão, da história e da luta do povo negro, que reforça o poder simbólico do racismo na sociedade. Soma-se 
a essa realidade a personificação do negro como perfil criminoso, em que o Código Penal de 1890 passou a criminalizar as manifestações da cultura negra, como a capoeira. Ademais, a presença do negro excluído incomodava a elite branca, que queria esquecer as atrocidades permitidas com essa população na escravidão, e passou a criminalizar as condutas de vadiagem e mendicância, atribuindo ao negro a culpa pela sua própria vulnerabilidade.

Em um giro contemporâneo, o cenário brasileiro ainda apresenta as marcas das desigualdades sociorraciais, em que os efeitos necropolíticos do racismo estrutural destinam os povos negros às zonas de esquecimento na sociedade, sem acesso ao mínimo existencial e à margem de qualquer projeto eficaz para promoção da igualdade sociorracial.

Sob essa égide, o direito à educação também reflete os efeitos necropolíticos do racismo estrutural quando não oportuniza o acesso igualitário dos alunos nos ambientes de aprendizagem. Ademais, o espaço educacional ainda se apresenta como um meio de reprodução do racismo e de exclusão dos povos negros.

3 As políticas afirmativas de inclusão racial no ensino superior e os entraves necropolíticos do racismo estrutural na permanência estudantil da população negra

A partir das ilações apresentadas e o delineamento das desigualdades sociorraciais na realidade brasileira é imperioso observar que os efeitos necropolíticos do racismo estrutural também ocupam os espaços de ensino e aprendizagem. Nesse contexto, a presente seção tem por objetivo analisar a construção das políticas afirmativas de inclusão no Brasil dentro do Ensino Superior, a fim de verificar a sua efetividade para a garantia do acesso à educação de forma igualitária.

Segundo Schwarcz (2019), o acesso à educação era negado aos negros, tendo em vista que, no sistema escravista, a educação era uma atividade pertencente apenas para a elite branca. Após a abolição da escravatura essa realidade não foi modificada de forma eficaz. A ausência de políticas assistenciais e de reparação dos anos de escravidão deixou a população negra à margem da concretude dos direitos humanos, em especial o direito à educação.

Nas lições de Moreira (2019), observamos que os negros libertos eram, em sua maioria, analfabetos e não foram oportunizados mecanismos para recuperar o atraso educacional da população negra em relação aos povos brancos, destinando-os em zonas de esquecimento, invisibilizados e desnudados de seus direitos essenciais para a sobrevivência humana.

$\mathrm{Na}$ realidade contemporânea, os efeitos necropolíticos do racismo são vivenciados nos ambientes escolares e universitários, quando se observa a desigualdade de estudantes brancos e 
negros nas salas de aula. Apesar de formalmente amparado pela garantia dos direitos fundamentais na Constituição da República Federativa do Brasil de 1988, a concretização de tais direitos encontra-se distante da realidade da população negra.

As universidades se consolidaram como espaços de segregação sociorracial, reproduzindo as marcas do racismo estrutural e dominados pela população elitizada e branca. Em um processo de permanência da invisibilização sociorracial da necropolítica brasileira, as universidades não vislumbravam questionar a ausência dos povos negros nos espaços acadêmicos, uma vez que, como salienta Carvalho (2006, p. 91) "foi justamente desse ambiente segregado que saíram todas as teorias que negam a existência de segregação racial no Brasil”.

Para Jaccoud (2009), as desigualdades sociorraciais passaram a ser questionadas a partir da década de 1970, tendo o crescimento dos movimentos sociais antirracistas que buscavam a igualdade de direitos entre brancos e negros. Com o processo de redemocratização do país, os movimentos sociais exigiram a igualdade e a inclusão da população negra nos espaços sociais, em especial no ambiente universitário.

O crescimento dos movimentos antirracistas ganhou ainda mais notoriedade com a promulgação da Constituição da República Federativa de 1988, que consagrou em seu artigo $5^{\circ}$, caput que "todos são iguais perante a lei, sem distinção de qualquer natureza, garantindo-se aos brasileiros e aos estrangeiros residentes no País a inviolabilidade do direito à vida, à liberdade, à igualdade, à segurança e à propriedade".

O direito à educação está previsto no artigo $6^{\circ}$ da Constituição da República de 1988 e se consagra como direito social, devendo ao Poder Público promover a sua concretização para todos os cidadãos sem distinção. Além disso, a Magna Carta de 1988 enunciou nos artigos 205 a 214, os princípios essenciais para a o ensino na realidade brasileira. Dentre os princípios elencados, destacamos a promoção da igualdade do acesso à educação, que reforça a necessidade da superação das desigualdades sociorraciais por meios de políticas públicas de reparação e assistenciais ao povo negro, ainda que tardia.

Mas, apesar dos avanços democráticos de formalização da garantia fundamental da promoção da igualdade sociorracial na Constituição da República de 1988, a realidade brasileira denota ainda desafios e entraves para a concretização desse direito, em especial a igualdade do acesso à educação superior no país. Segundo Carvalho (2006), em análise de pesquisa publicada pela Revista Fórum indica que, até 1997, apenas 1,8\% da população negra, entre 18 e 24 anos, cursava ou já tinha finalizado curso de graduação no Brasil. 
Em 2001, ocorreu a III Conferência contra o Racismo, a Xenofobia e as Intolerâncias, em Durban, na África do Sul, que fortaleceu os movimentos negros de luta pelo acesso igualitário no ensino superior. Ademais, o Brasil se comprometeu a implantar ações afirmativas para promover a educação igualitária com vistas a reduzir as desigualdades sociorraciais nas universidades. Diante dessa conjuntura, algumas universidades brasileiras implementaram as primeiras políticas de cotas raciais para ingresso no ensino superior, tais como a Universidade do Estado do Rio de Janeiro e a Universidade de Brasília.

Segundo a Universidade do Estado do Rio de Janeiro (2020), a Assembleia Legislativa do Rio de Janeiro aprovou a destinação de $40 \%$ das vagas dos cursos de graduação para os autodeclarados negros e pardos, representando uma conquista para a adesão de políticas de educação igualitária no país.

Já a Universidade de Brasília (2018) foi a pioneira das universidades federais a implantar políticas afirmativas sociorraciais, reservando vagas para estudantes oriundos de escola pública, estudantes negros e indígenas, em 2003. Diante desse cenário, em 2010, a Lei Federal no 12.288/2010 instituiu o Estatuto da Igualdade Racial, que determinou a adoção das políticas afirmativas para a inclusão da população negra na realidade social como instrumento de reparação histórica, além de estabelecer a necessidade de combate ao racismo estrutural.

Nessa linha de intelecção, em 2012 foi sancionada a Lei de Cotas - Lei no 12.711/2012, em que todas as instituições federais de ensino superior devem reservar obrigatoriamente vagas para cotas raciais, a fim de promover o acesso da população negra no ensino superior.

Nesse contexto, as políticas afirmativas de inclusão racial representam a possibilidade de efetividade da educação igualitária, oportunizando o acesso ao ensino superior da população negra vulnerabilizada. Conforme salienta Gomes (2003), as ações afirmativas consistem, portanto, em políticas públicas ou privadas que tem como intento dirimir os impactos das desigualdades, dando oportunidade de acesso à educação aos grupos vulnerabilizados, com vagas reservadas. Ocorre que, apesar da pertinência das políticas afirmativas com a adoção do sistema de cotas é importante destacar que as ações de reparação histórico-social e de inclusão da população negra não se resume a disponibilidade de vagas no ensino superior.

É preciso que as ações afirmativas sejam políticas de transformação social, permitindo modificar a realidade da população negra a fim de que esta consiga alcançar espaços que antes eram restritos para a população branca. Ademais, as ações de afirmação devem estar pautadas na promoção de políticas de permanência estudantil, para valorização da identidade negra e do 
reconhecimento da desigualdade racial que o Brasil enfrenta, com vistas à extinção do racismo e dos efeitos necropolíticos na sociedade brasileira.

Nesse sentido, Santos (2009) afirma que as ações afirmativas podem romper estigmas das desigualdades sociorraciais capazes de mudar os paradigmas do racismo estrutural no país. Por esse aspecto que a referida autora (2009) defende a adoção de políticas de permanência material e simbólica. A permanência material é a possibilidade do discente que ingressou por cotas ter condições socioeconômicas de concluir o curso, tendo auxílio para comprar material didático, auxílio transporte e alimentação e até mesmo a promoção de residências universitárias para o aluno que não possui condições de alugar imóvel para residir durante a graduação.

Já a permanência estudantil simbólica é a transformação das estruturas sociais por meio do caráter de transformação do ensino, pautado em uma educação baseada em valores e na concretização de direitos humanos, trazendo à baila a reflexão sobre o racismo estrutural para propor a erradicação das consequências necropolíticas das desigualdades na sociedade.

Ocorre que a realidade que se delineia demonstra que ainda estamos distantes de alcançar a efetiva justiça sociorracial e a verdadeira inclusão no ensino superior, tendo em vista, que as políticas de permanência material e simbólica ainda são precárias nas universidades, revelando o engessamento do racismo de forma recreativa nos espaços universitários, que silenciam a participação da população negra.

Em observância dos dados estatísticos da Síntese de Indicadores Sociais do Instituto Brasileiro de Geografia e Estatística - IBGE (2019), a quantidade de jovens negros no ensino superior avançou, mas ainda não representa metade da taxa dos jovens brancos nas universidades. A proporção de jovens negros ou pardos no ensino superior passou de 50,5\% em 2016 para 55,6\% em 2018. No entanto, quando se observa os dados gerais da população, verifica-se que essa proporção entre os brancos é de 78,8\%.

Além disso, ao se observar os dados da ANDIFES (2019), 51,2\% da população das Instituições Federais de Ensino Superior é negra. Por outro lado, a pesquisa revela que a ausência de políticas de permanência impede a efetividade da igualdade do acesso ao ensino. De acordo com os dados do IBGE (2019) apenas 18,3\% dos negros haviam concluído a educação superior, enquanto os brancos somam $36,1 \%$.

Outra marca dos entraves necropolíticos no acesso igualitário ao ensino superior diz respeito às condições de vida econômica daqueles que concluíram a graduação. Conforme relatório do IBGE (2019), 64,2\% da população negra que se formou no ensino superior está desempregada. 
Dentro da análise do quadro de desemprego geral, percebe-se ainda que os negros representam cerca de $47,3 \%$ dos trabalhos informais enquanto os brancos apenas $34,6 \%$.

$\mathrm{Na}$ análise dos dados estatísticos de ocupação de cargos de chefia ou gerência do IBGE (2019), também verificamos que a população negra representa apenas $29,9 \%$ enquanto os brancos ocupam 68,36\%. Essa conjuntura revela que, a população negra que consegue concluir a graduação não está sendo inserida no mercado de trabalho de forma igualitária, com cargos e condições econômicas inferiores aos brancos.

No cotejo da análise das políticas de permanência simbólicas de transformação social da educação para erradicar as marcas do racismo estrutural na sociedade, observamos que ainda estamos distantes da justiça sociorracial. Verifica-se que o protagonismo negro é esquecido e desvalorizado. Segundo Fanon (2008), os poucos negros que ocupam os espaços universitários reproduzem as visões eurocêntricas da história e da cultura dos ancestrais africanos que vivenciaram a escravidão. Ademais, há uma preferência de autores e pensadores brancos e europeus no ambiente acadêmico, em detrimento do pensamento filosófico de negros na academia. Essa anulação dos autores negros faz parte da promoção do racismo recreativo, que se desenvolve de forma silenciosa e impede o rompimento com os paradigmas das desigualdades sociorraciais.

Nessa esteira, os espaços universitários acabam se tornando neutralizados pela ação do racismo estrutural, incapacitando os alunos para a criticidade da formação do ensino superior. Nesse diapasão, a universidade acaba construindo muros indeléveis da necropolítica brasileira, a partir do momento em que não rompe com o sistema de supremacia de dominação do pensamento da população branca.

Nesse contexto, o racismo se reveste de novas formas e petrifica na anulação das vozes negras no debate acadêmico, que se desnuda no epistemicídio da cultura africana, na falta de oportunidade da população negra assumir a docência das universidades e no silenciamento da identidade dos povos negros. Conforme salienta Silva (2003), o racismo epistêmico dá novos contornos mais cruéis para a necropolítica brasileira, uma vez que a ausência de uma memória coletiva e científica de pessoas negras nos conduz ao processo de esquecimento das vozes negras, em que as novas gerações não têm em quem se espelhar para acreditar em um futuro transformador e igualitário.

Soma-se a essa realidade os discursos de ódio contra a política de cotas raciais que demonstram que a sociedade nunca superou as amarras do racismo e revelam a intolerância da efetividade da igualdade no contexto do ensino superior. Tal conjuntura leva a transformação do 
espaço democrático de ensino em um ambiente de discriminação e de marginalização da população negra.

4 A aplicabilidade dos métodos restaurativos no ambiente universitário como mecanismo para promoção da educação igualitária

Diante dos entraves necropolíticos do racismo estrutural para a efetividade da educação igualitária e para o fomento da justiça sociorracial, impende registrar a importância da criação de mecanismos para promover o fortalecimento das políticas afirmativas de permanência estudantil da população negra no ensino superior, a fim de que a realidade desigual que se delineia seja transformada pela educação e conscientização dos cidadãos para erradicar as marcas do racismo.

Nesse aspecto, compreende-se que, ao se buscar o fortalecimento das políticas afirmativas para dirimir os impactos necropolíticos do racismo, o ensino superior assume o seu papel de transformação social, pautado em uma educação baseada na concretização dos direitos humanos de forma igualitária, por meio da criação da consciência coletiva sobre as nuances do racismo recreativo e simbólico presentes nas universidades, que se apresentam como reflexos da sociedade.

Nessa linha de intelecção, o uso do espaço universitário para fomentar debates e discutir as faces simbólicas do racismo faz parte da construção da autonomia das universidades como instrumentos de transformação social. Nas lições de Freire (1996), a educação tradicional e elitizada pode ser substituída por uma educação dialética e libertadora, que reconheça as suas próprias mazelas sociais que impedem a educação igualitária e, a partir disso, possam buscar mecanismos para mudar o cenário de desigualdade dentro e fora dos muros das universidades.

Conforme salienta Mazzilli (2011), a verdadeira materialização da igualdade sociorracial só será possível por meio do fortalecimento da adoção de políticas afirmativas de reparação histórica do período da escravidão, no intuito de dar oportunidades para os povos vulnerabilizados que sempre ficaram à margem social, em especial no acesso à educação.

Segundo Freire (2012), a educação é responsável por analisar as contradições que a sociedade vivencia para poder transformá-la. Nesse sentido, a educação tem o papel de descortinamento das raízes do racismo estrutural e de redução dos discursos de ódio no ambiente universitário de discriminação racial, por meio da transformação social fomentada pelas atividades de ensino, pesquisa e extensão.

A partir dessa conjuntura, a Justiça Restaurativa apresenta-se como mecanismo necessário para superação dos entraves necropolíticos dentro do ambiente universitário, a fim de conduzir a construção de uma consciência coletiva por meio do diálogo e da escuta ativa das vozes silenciadas. 
Os métodos restaurativos conduzem à transformação do ambiente educacional em um espaço plural e de respeito aos direitos humanos de todos os povos.

Para compreender a inserção das práticas restaurativas no ambiente educacional como instrumento de mitigação da estrutura simbólica do racismo estrutural e dos seus efeitos necropolíticos é imperioso analisar as bases axiológicas da Justiça Restaurativa e as suas contribuições para a pacificação social e alcance da justiça igualitária.

Segundo salienta Tourinho (2017), a Justiça Restaurativa é uma proposta de resolução dos conflitos por meios de métodos consensuais com vistas à pacificação social, por meio do empoderamento das partes envolvidas e pela comunidade próxima, quando for possível. Verificase, portanto, o caráter multifacetário das práticas restaurativas que podem ser utilizadas dentro do ambiente processual para composição dos danos, mas também podem ser empregadas na esfera comunitária como instrumento de transformação social.

Nesta esteira, Zehr (2018) afirma que a Justiça Restaurativa pode ser definida como um novo modelo de justiça que alcança todas as esferas da sociedade. Por esse aspecto, os métodos restaurativos reclamam o cumprimento dos direitos humanos não apenas no contencioso processual, mas nos comportamentos e nas vivências da sociedade.

Como leciona Braithwaite (2002), os métodos restaurativos têm suas origens fundadas na prática da justiça comunitária, estabelecendo o diálogo e a participação ativa dos envolvidos e da comunidade para superação do evento traumático, lançando bases para a transformação da realidade que se delineia. Vejamos:

\footnotetext{
A Justiça Restaurativa surgiu muito antes do que se conseguiu catalogar. Suas práticas nos remetem a abordagem restaurativa das assembleias públicas (moots) dos povos germânicos que varreu a Europa após a queda de Roma (Berman 1983, pp. 53-56); Hindus indianos tão antigos quanto a civilização védica (6000-2000 aC; Beck, 1997, p. 77) para quem aquele que expia é perdoado (Weitekamp, 1989); e antigo budista, taoísta, e tradições confucionistas que se vê misturado com o Ocidente influencia hoje em dia. Norte da Ásia (Haley 1996). A Justiça Restaurativa estava implícita nas ações humanas que buscavam humanizar as penas, mas que, por vezes, era confundida com o abolicionismo penal, com a teoria do etiquetamento. Ela vai muito mais longe, ela quebra a visão do criminoso, da sociedade, e da vítima e tudo se funda no diálogo, por isso a possibilidade variada de formas porque tudo que permita integrar, repensar e reformular o direito tem sua base restaurativa. (BRAITHWAITE, 2002, p. 3, tradução nossa).
}

Diante desse arcabouço teórico, os métodos restaurativos apresentam-se como multifacetados e plurais, tendo por base a composição do conflito de forma pacífica e com vistas à reintegração social. Por esse aspecto, o presente estudo não pretende esgotar a investigação de todos os modelos de Justiça Restaurativa, uma vez que esta é uma ciência em crescente construção 
que pode se adaptar a novas conjunturas que tem como objetivo alcançar a efetividade da justiça por meio da pacificação social.

Nesta esteira, a pesquisa irá trazer as principais concepções valorativas que norteiam a construção da Justiça Restaurativa e que são observadas nos processos restaurativos multifacetados. Conforme salienta Tourinho (2017), as práticas restaurativas trazem em seu bojo os valores da voluntariedade, do diálogo, do respeito e do empoderamento das partes para conduzir à reparação e à transformação social. Vejamos:

A Justiça Restaurativa como um conjunto de práticas multifacetárias, projetadas nos
domínios do sistema jurídico-penal, e orientadas à resolução de conflitos, em uma
perspectiva de reconhecimento da sua dimensão interrelacional, por meio de
procedimentos com participação ativa da vítima, do infrator e da comunidade, quando
necessário e possível, assumindo finalidades plurais, no sentido de possibilitar a reparação
dos danos suportados pela vítima, a reintegração do autor do delito, a partir do seu
encontro com as consequências decorrentes de sua conduta, tendo em vista a promoção
da pacificação social. As práticas restaurativas devem ser balizadas, outrossim, pela
voluntariedade e autonomia de vontade dos intervenientes. (TOURINHO, 2017, p. 131).

Por essa perspectiva, a Resolução $n^{\circ} 12 / 2002$ do Conselho Econômico e Social da Organização das Nações Unidas - ONU incentivou o uso modelos restaurativos para cada conflito social, partindo do pressuposto de que qualquer ação que se fundamente na abertura do diálogo e na condução para a reparação e transformação da consciência coletiva é um processo restaurativo. Vejamos:

1. Programa de Justiça Restaurativa significa qualquer programa que use processos restaurativos e objetive atingir resultados restaurativos

2. Processo restaurativo significa qualquer processo no qual a vítima e o ofensor, e, quando apropriado, quaisquer outros indivíduos ou membros da comunidade afetados por um crime, participam ativamente na resolução das questões oriundas do crime, geralmente com a ajuda de um facilitador. Os processos restaurativos podem incluir a mediação, a conciliação, a reunião familiar ou comunitária (conferencing) e círculos decisórios (sentencing circles).

3. Resultado restaurativo significa um acordo construído no processo restaurativo. Resultados restaurativos incluem respostas e programas tais como reparação, restituição e serviço comunitário, objetivando atender as necessidades individuais e coletivas e responsabilidades das partes, bem assim promover a reintegração da vítima e do ofensor. (ORGANIZAÇÃO DAS NAÇÕES UNIDAS, Resolução no 12/2002).

No cenário brasileiro, as práticas restaurativas são incentivadas pela Resolução no 225/2016 do Conselho Nacional de Justiça que estimula a adoção do olhar diferenciado da vivência restaurativa para reparação social. Ademais a referida resolução atribui como função do Poder Judiciário e das instituições sociais a adoção da solução consensual dos conflitos para a pacificação das comunidades, reforçando o caráter interdisciplinar da Justiça Restaurativa. 
Em atenção ao ambiente da educação superior, observamos que a prática educacional se efetiva de forma igualitária e justa quando se cultiva as bases restaurativas na convivência universitária, por meio da criação de espaços participativos e integradores, capazes de escutar a realidade social de toda comunidade plural que a compõem, promovendo o respeito à diversidade e a inclusão social dos grupos vulnerabilizados.

Dessume-se que a Justiça Restaurativa é um pressuposto fundamental para uma educação pautada na gestão democrática, no diálogo e na promoção da paz dentro da realidade do ensino, por meio da realização de práticas restaurativas que buscam ressignificar as fragilidades sociais e capacitar a comunidade para a concretização da igualdade.

Em consonância com essa premissa, Tourinho (2017) destaca o papel social da Justiça Restaurativa como sistema multiportas de construção de novos caminhos para velhos problemas sociais que nunca foram superados. Nesse cotejo, o combate ao racismo estrutural e aos seus efeitos necropolíticos ganham novos contornos por meio de uma justiça que prime pela pacificação e conscientização da comunidade, a partir da criação de pontes de reparação histórica e inclusão da população negra vulnerabilizada.

Para compreensão das finalidades propostas da pesquisa, optamos por estudar três modelos restaurativos eficazes para o contexto educacional, quais sejam: a escuta ativa, as conferências e os círculos de paz. Segundo salienta Pallamolla (2009), a integração das conferências e dos círculos de paz permitem criar mecanismos para alcançar a ruptura com os entraves dos conflitos e propor a conscientização por meio do diálogo e da pacificação social.

Depreende-se das lições de Dignan e Marsh (2003) que a escuta ativa é o modelo restaurativo que concretiza o empoderamento da população, para que esta possa de forma direta relatar as suas percepções dos problemas sociais enfrentados, a fim de conduzir para uma resposta eficaz. No cenário educacional, a escuta ativa está prevista no Guia Prático para Educadores "Diálogos e práticas restaurativas nas escolas", elaborado pelo Ministério Público do Estado de São Paulo e pela Secretaria de Educação do Estado de São Paulo e organizado por Nunes (2018), que prevê a construção de diálogos significativos entre o espaço educacional e a sociedade, a fim de buscar a transformação social.

Os diálogos significativos são a principal base para as práticas restaurativas na gestão educacional democrática, pois o diálogo promove a colaboração, a intersubjetividade, a reelaboração do problema e a humanização das relações. A partir dessa conjuntura, dentro do ambiente universitário, a escuta ativa e os diálogos significativos permitem a expressão dos alunos sobre as mazelas sociais enfrentadas. 
Ao se articular o diálogo significativo no cenário das universidades vislumbra-se a possibilidade de aproximação do ensino com a extensão universitária para dar voz às classes silenciadas e buscar técnicas de reparação por meio da transformação. No que tange a análise do racismo estrutural simbólico e seus entraves necropolíticos, os diálogos e a escuta ativa são verdadeiras ferramentas de oportunizar a visibilidade para a população que sempre foi esquecida. Ademais, por meio da escuta ativa será possível que os alunos e a comunidade identifiquem e reflitam sobre as práticas simbólicas do racismo recreativo, que se petrifica de forma silenciosa na realidade social.

Para a adoção desse modelo restaurativo tem sido incentivado nas escolas e nas universidades a criação de políticas de permanência estudantil, com canais de atendimento para relatar os cenários de racismo que se vivencia no ambiente acadêmico, a fim de que sejam tomadas medidas eficazes para a erradicação das desigualdades sociorraciais no ambiente universitário e fora dele. Ademais, a escuta ativa permite o acolhimento e o respeito com a dor e o sofrimento alheio, estabelecendo relações de empatia para que se busque a reflexão sobre a necessidade de construção de uma justiça e uma educação igualitária para que toda a coletividade se sinta reconhecida e integrada no seio social.

Por meio da escuta ativa e dos diálogos significativos permite-se a adoção de uma gestão democrática do ensino, trazendo a construção coletiva do projeto político-pedagógico dos cursos de graduação, a consolidação da participação estudantil por meio de centros acadêmicos, movimentos sociorraciais, grupos de estudos que discutam o racismo estrutural para conhecimento de toda a população.

Esse novo olhar da Justiça Restaurativa dentro do ambiente universitário permite resgatar as memórias silenciadas da população negra em um processo de reconstrução da história da escravidão sob o olhar de quem teve seus ancestrais humilhados e oprimidos e não mais pela versão do colonizador. Tal proposta, permite utilizar a escuta ativa para a integração de autores negros nos planos pedagógicos das instituições, a fim de erradicar o epistemícidio da decolonialidade. Nessa esteira, as universidades devem também oportunizar a criação de políticas afirmativas de permanência para inclusão sociorracial no quadro de docentes e permitir que a população negra ocupe todos os espaços sem desigualdade, como política de reparação histórico-social.

Outro modelo restaurativo são as conferências que, segundo Pranis (2011) revelam o compromisso social de conscientização coletiva. As conferências são mediações ampliadas com a participação da comunidade sobre a reflexão do conflito social. No âmbito da educação superior, 
as conferências permitem a realização das práticas de extensão como mecanismos de transformação da sociedade.

Quando se analisa o racismo estrutural sob o viés restaurativo das conferências, percebese que estas são essenciais para desmistificar o racismo simbólico enraizado nos discursos de ódio e nas ações necropolíticas de discriminação racial, trazendo à baila a necessidade de construção de uma educação com compromisso na efetivação dos direitos humanos a partir da reflexão social.

Por essa linha de intelecção, as conferências dentro dos espaços universitários podem ser incorporadas com palestras e rodas de conversas, abertos para a comunidade para que se tenha conhecimento das dimensões histórico-sociais do racismo na realidade brasileira, com vistas a buscar a erradicação das amarras das correntes da escravidão que ainda pesam sobre a população negra. Ademais, as conferências permitem desmistificar os discursos de ódio contra as políticas afirmativas raciais, como o sistema de cotas, por meio da informação sobre a importância dessas políticas para a promoção da educação igualitária e a justiça sociorracial.

Já os círculos de construção de paz são modelos restaurativos que trabalham com a técnica da comunicação não violenta para quando o conflito já se instaurou no ambiente social. Nas lições de Brancher (2017), os círculos de construção de paz consistem em experiências restaurativas que, por meio do diálogo e do respeito, levam às partes a reflexão do conflito, indagando as causas e consequências. Em atenção ao contexto do racismo no ambiente universitário, os círculos de paz podem promover a superação do evento traumático ocorrido no espaço educacional, para que a vítima se sinta acolhida pela gestão acadêmica e pela comunidade e para que o ofensor compreenda o seu erro e não venha a práticas novas condutas discriminatórias no meio acadêmico e fora da universidade.

Segundo salienta Tourinho (2017), os círculos de construção de paz são divididos em três momentos: os pré-círculos, os círculos propriamente ditos e os pós-círculos. No momento do précírculo, as partes se apresentam de forma separada e são convidadas a relatar suas experiências, para que haja o desprendimento com as mágoas e possa alcançar a superação do evento traumático.

Após esse período, são realizados os círculos em si, em que, por meio da voluntariedade, os indivíduos são convidados a dialogarem e ressignificarem o evento que vivenciaram, colocandose na posição do outro, buscando estimular o empoderamento das partes e a criação da consciência coletiva para a prevenção social, traçando meios e métodos para superação e reparação dos danos. Em seguida, são realizados os momentos de pós-círculos, que se constituem em encontros para a promoção da pacificação social, com participação de próximos aos envolvidos por meio das 
conferências, a fim de que possam estimular o resgate ao respeito ao cidadão de forma integrada e inclusiva.

\section{Considerações finais}

A educação encontrou na Justiça Restaurativa, através de um processo de formação cuidadoso, persistente e ativo do cidadão, um poderoso aliado na transformação social, no respeito aos direitos humanos e na busca de uma sociedade mais justa e igualitária para todos. Trata-se de instrumentos de desconstrução do racismo estrutural enraizados na sociedade, buscando romper com os ciclos necropolíticos do racismo no contexto universitário, com vistas à promoção da justiça sociorracial.

A partir da educação dialogada e de métodos de empoderamento das partes e da sociedade, a Justiça Restaurativa se apresenta como elemento fundamental para a pacificação social e a criação de uma consciência cidadã coletiva, que busque resgatar o respeito aos direitos humanos dos indivíduos, promovendo debates para a integração de todos os cidadãos, com vistas à redução da cultura do ódio e da seletividade social.

\section{Referências}

AGAMBEN, Giorgio. Homo sacer: o poder soberano e a vida nua I. Tradução de Henrique Burigo. Belo Horizonte: Editora UFMG, 2007.

ALMEIDA, Silvio Luiz de. O que é racismo estrutural? Belo Horizonte (MG): Letramento, 2018.

ANDIFES. V Pesquisa do perfil socioeconômico e cultural dos estudantes de graduação das universidades federais. Brasília, 2019.

BRANCHER, Leoberto Narciso. Justiça Restaurativa: a cultura de paz na prática da Justiça. Disponível em: <http://jii.ti.rs.gov.br/jij_site/docs/JUST_RESTAUR/VIS\%C3O+GERAL+JR_0. Acesso em 17/02/2017.

BRAITHWAITE, John. Restorative Justice and Responsive Regulation. Oxford University Press, Inc.198 Madison Avenue, New York, 2002.

BRASIL. Constituição (1988). Constituição da República Federativa do Brasil. Brasília, DF, Senado, 2013.

BRASIL, Lei n. 12.711, de 29 de agosto de 2012. Diário Oficial da União, Brasília, DF, 30 ago. 2012. Disponível em: https://www.planalto.gov.br/ccivil_03/_ato2011-2014/2012/lei/112711.htm. Acesso em: 15.08.2021. 
BRASIL, Lei ñ 12.288, de 20 de julho de 2010.

Institui o Estatuto da Igualdade Racial; altera as Leis nos 7.716, de 5 de janeiro de 1989, 9.029, de 13 de abril de 1995, 7.347, de 24 de julho de 1985, e 10.778, de 24 de novembro de 2003. Diário Oficial da União, Brasília, 20 de julho de 2010. Disponível em:

https://www.planalto.gov.br/ccivil_03/_ato2007-2010/2010/lei/112288.htm. Acesso em 15.08.2021.

BRASIL. Conselho Nacional de Justiça. Resolução n. 225, de 12 de julho de 2016. Disponível em: <http://www.cnj.jus.br/busca-atos-adm?documento=1241>. Acesso em 25 out. de 2017.

CARVALHO, José Jorge de. O confinamento racial do mundo acadêmico brasileiro. Revista USP, n.68, São Paulo, 2006.

DIGNAN, Jim. MARSH, Peter. Restorative justice and family group conferences in England: current state and prospects. In: MORRIS, Alisson. MAXWELL, Gabrielle. Restorative justice for juveniles - conferencing, mediation, and circles. Portland: Hart Publishing, 2003.

DIWAN, Pietra. Raça Pura. Uma História da Eugenia no Brasil e no mundo. São Paulo: Contexto, 2007.

FANON, Franz. Pele negra, máscaras brancas. Tradução de Renato da Silveira. Salvador: EDUFBA, 2008.

FERNANDES, Florestan. A integração do negro na sociedade de classes: vol. 1. 5.ed. São

Paulo: Globo, 2008.

FOUCAULT, Michel. Em defesa da sociedade: curso no Collège de France. Tradução de Maria Ermantina Galvão. São Paulo: Martins Fontes, 1999.

FREIRE, Paulo. Pedagogia da Autonomia: Saberes Necessários à Prática Educativa. 31ª ed. São Paulo: Paz e Terra, 1996.

FREIRE, Paulo. Extensão ou Comunicação? Rio de Janeiro: Editora Paz e Terra, 2012. FREYRE, Gilberto. Casa grande \& senzala: formação da família brasileira sob o regime da economia patriarcal. Edição crítica de Guillermo Giucci, Enrique Larreta, Edson Fonseca. Paris: Allca XX, 2002.

GÓES, Luciano. Entre a abolição e o abolicionismo penal: insurgência marginal crítica por uma sociologia do sistema de controle racial brasileiro. In: GÓES, Luciano (org.). 130 anos de (des)ilusão: a farsa abolicionista em perspectiva desde olhares marginalizados. Belo Horizonte: Editora D’Plácido, 2019.

HILÁRIO, Leomir C. Da Biopolítica à necropolítica: variações foucaultianas na periferia do capitalismo. Sapere Aude, v. 7, 2016.

HOLANDA, Sérgio Buarque de. Raǐres do Brasil. São Paulo: Companhia das letras, 1995.

IBGE - INSTITUTO BRASILEIRO DE GEOGRAFIA E ESTATÍSTICA, 2019.

Desigualdades Sociais por Cor ou Raça no Brasil, 2019. Rio de Janeiro: IBGE. 
GOMES, Joaquim Benedito Barbosa. O debate constitucional sobre as ações afirmativas. In: Santos, Renato Emerson dos; Lobato, Fátima (Orgs.). Ações afirmativas: políticas públicas contras desigualdades raciais. Rio de Janeiro: DP \& A Editora, 2003. p. 15-57.

JACCOUD, Luciana. A construção de uma política de promoção da igualdade racial: uma análise dos últimos 20 anos. Instituto de Pesquisa Econômica Aplicada - IPEA. Brasília: Ipea, 2009.

MAZZILLI, Sueli. Ensino, pesquisa e extensão: reconfiguração da universidade brasileira em tempos de redemocratização do Estado. Revista Brasileira de Política e Administração da Educação Periódico científico editado pela ANPAE, [S.1.], v. 27, n. 2, dez. 2011. ISSN 2447-4193.

Disponível em: https://seer.ufrgs.br/rbpae/article/view/24770. Acesso em: 14.06.2021.

MBEMBE, Achille. Necropolitica: biopoder, soberania, estado de exceşão, politica da morte. Trad. Renata Santini. São Paulo: n-1, 2018a.

MBEMBE, Achille. Crítica da razão negra. Trad. Sebastião Nascimento. São Paulo: n-1, 2018b.

MOREIRA, Adilson. Racismo Recreativo. Coleção Feminismos Plurais, São Paulo, 2019.

NASCIMENTO, Abdias do. O Genocídio do Negro Brasileiro: Processo de um Racismo Mascarado. Rio de Janeiro: Paz e Terra, 1978.

NASCIMENTO, Abdias, O Quilombismo: Documentos de Uma Militância Pan-Africana. Prefácio de Kabengele Munanga, texto de Elisa Larkin Nascimento E Valdecir Nascimento. 3.Ed Rev. São Paulo. Editora Perspectiva-IPEAFRO; Rio de Janeiro, 2019.

NUNES, Antonio Carlos Ozório. Diálogos e práticas restaurativas nas escolas: guia prático para educadores. São Paulo: Ministério Público do Estado; Secretaria da Educação do Estado, 2018.

ORGANIZAÇÃO DAS NAÇÕES UNIDAS. Resolução 2002/12 de 24 de julho de 2002, p. sem número. Conselho Econômico e Social.

PALLAMOLLA, Raffaella da Porciuncula. Justiça restaurativa: da teoría à prática. São Paulo: IBCCrim, 2009.

PRANIS, Kay. Processos Circulares. São Paulo: Palas Athena, 2011.

RIBEIRO, Darcy. O Povo Brasileiro: A formação e o sentido do Brasil. São Paulo: Companhia das Letras, 2006.

SANTOS, Dyane Brito Reys (2009). Para além das cotas: a permanência de estudantes negros no ensino superior como política de ação afirmativa. Tese (Doutorado) em Educação. Universidade Federal da Bahia.

SCHWARCZ, Lilia Moritz. Sobre o autoritarismo brasileiro. São Paulo: Companhia das Letras, 2019. 
SILVA, Petronilha Beatriz Gonçalves. Negros na Universidade e produção de conhecimento. In: SILVA, Petronilha Beatriz Gonçalves; SILVERIO, Valter Roberto (Org.). Educação e ações afirmativas: entre a injustiça simbólica e a injustiça econômica. Brasília: Instituto Nacional de Estudos e Pesquisas Educacionais Anísio Teixeira, 2003.

TOURINHO, Luciano de Oliveira Souza. Justiça Restaurativa e Crimes Culposos: Contributo à Construção de um Novo Paradigma Jurídico-Penal no Estado Constitucional de Direito. Rio de Janeiro: Editora Lumen Juris, 2017.

UNIVERSIDADE DO ESTADO DO RIO DE JANEIRO. Sistema de Cotas. Disponível em: https://www.uerj.br/inclusao-e-permanencia/sistema-de-cotas/. Acesso em 14.06.2021.

UNIVERSIDADE DE BRASÍLIA. Aprovação das cotas raciais na UnB completa 15 anos. Disponível em: https://www.noticias.unb.br/76-institucional/2319-aprovacao-das-cotas-raciais-na-unbcompleta-15-anos. Acesso em 20.07.2021.

ZEHR, Howard. Trocando as Lentes: Justiça Restaurativa para o nosso tempo. 25. ed. Tradução de Tônia Van Acker. São Paulo: Palas Athena 2018. 